Research Article

\title{
Research on the Balanced Relationship between Online Consumer Behavior and E-Commerce Service Quality Based on 5G Network
}

\author{
Yuna Si iD \\ Xijing University, Xi'an 710123, China \\ Correspondence should be addressed to Yuna Si; siyuna0904@mail.bnu.edu.cn
}

Received 14 January 2021; Revised 27 January 2021; Accepted 20 February 2021; Published 9 March 2021

Academic Editor: Hsu-Yang Kung

Copyright (C) 2021 Yuna Si. This is an open access article distributed under the Creative Commons Attribution License, which permits unrestricted use, distribution, and reproduction in any medium, provided the original work is properly cited.

\begin{abstract}
In order to better explore the consumer psychology activities of consumers and reduce the cost control risks of enterprises, this article aims to explore the relationship between online consumer behavior and e-commerce service quality and hopes to study e-commerce by dividing online consumer groups. This article uses 5G technology to track consumer consumption habits and consumption costs. First, according to the existing literature and qualitative interviews with online consumers, it is determined that the e-commerce service quality evaluation factors are the core service quality-related system reliability, efficiency, guarantee and completion, and the quality of after-sales service. Then, based on the data obtained from the questionnaire, SPSS statistical analysis software was used to analyze the reliability of the sample variables, thereby improving the quality of the sample data. We perform descriptive statistical analysis on these measurement items. Each attribute calculates the importance of each dimension. Through the analysis of experimental cases, it can be seen that the use of $5 \mathrm{G}$ technology can well match consumers' consumption habits and message needs and can evaluate the quality of e-commerce services more accurately and scientifically.
\end{abstract}

\section{Introduction}

The concept of transaction cost was derived from the 1937 paper "The Nature of Business" by Nobel Prize-winning economist Professor Ronald Coase. Coase used this concept to explain the emergence of the company. He pointed out that the market transaction process is costly, and the company appears because its transaction cost is relatively small compared to the market transaction cost. It should be pointed out that before Coase proposed the concept of transaction cost, the study of neoclassical economics was based on the assumption that the transaction cost was zero and thus to some extent lacked persuasiveness to the real world. The presentation of the transaction cost theory specifies constraints on property rights and transaction costs that have a decisive influence on behavior [1]. In the 5G era, there will be no pure e-commerce platform. In other words, any platform related to the cloud will have the attributes of e-commerce. This has already begun to take shape in the latter part of the $4 \mathrm{G}$ era, and a final blow to the $5 \mathrm{G}$ is still needed to completely disrupt the future. $5 \mathrm{G}$ networks can more quickly explore business opportunities in the e-commerce market, increase the scope and depth of e-commerce services, and capture the market horizontally and vertically.

After Coase, some researchers have differently defined the concept of transaction costs from different research perspectives. For example, Arrow used the "transaction cost" to describe the "cost of economic system operation." It can be seen as a series of institutional costs, including information costs, negotiation costs, the cost of developing and implementing a contract, defining and controlling the cost of property rights, the cost of supervision and management, and the cost of institutional changes, in short, including everything that does not happen directly in the production process [2]. As a master of transaction cost theory, Williamson extends transaction costs to all economic institutional environments. He believes that transaction costs include ex ante transaction costs and ex post transaction costs. Ex ante transaction costs include drafting, negotiating, and maintaining the cost of executing an agreement. The posttransaction costs include unsuitable costs incurred when 
the transaction deviates from the required criteria; the cost of controversy; the cost associated with the establishment and operation of the management organization; and the cost of mortgages for which the security guarantee is effective. Although the above scholars have different definitions of transaction costs, they have clearly outlined the basic composition of transaction costs. Obviously, the transaction cost is the sum of the various costs of money, knowledge, time, physical strength, etc. that people pay to complete the transaction. It tells us that both parties to the transaction have a hidden rule, that is, the completion of the transaction depends on whether the revenue is greater than the payment transaction cost. The paper's design method is shown in Figure 1.

The research contributions of this article include the following:

(1) This article uses 5G technology to track consumer consumption habits and consumption costs.

(2) We use SPSS statistical analysis software to analyze the reliability of sample variables, thereby improving the quality of sample data.

(3) We perform descriptive statistical analysis on the measurement items, so that each attribute is well calculated.

The rest of this paper is organized as follows. Section 2 discusses research on the theory of network consumer behavior from the perspective of transaction cost, followed by the research on measurement factors of e-commerce service quality designed in Section 3. Relationship model and empirical research on network consumer behavior and e-commerce service quality are discussed in Section 4. Section 5 concludes the paper with summary and future research directions.

\section{Research on the Theory of Network Consumer Behavior from the Perspective of Transaction Cost}

\subsection{The Application of Transaction Cost Theory in the Inter-} pretation of Online Consumer Behavior. Williams has studied his transaction cost theory in three mutually influential dimensions (i.e., trading uncertainty, asset specificity, and trading frequency) and two main assumptions of human behavior (limited rationality and opportunism). The uncertainty of the transaction mainly refers to the uncertainty that the future situation may not be accurately predicted due to factors such as bounded rationality and information asymmetry, which leads to the uncertainty of the occurrence of incidents; asset specificity refers to the persistence used to support special transactions. In persistent investment, assets are often difficult to use for other purposes; the frequency of transactions refers to the frequency of transactions [3]. Among the human behavior factors, bounded rationality refers to the limited nature of the transaction subject to its own cognitive ability and rationality; opportunism refers to the deceptive strategic behavior adopted by the transaction subject based on the pursuit of maximization of its own interests. Based on these factors, the transaction cost theory explains why the transaction subject chooses a transaction form. Due to the impact of transaction cost factors on consumer behavior, some scholars have tried to use the transaction cost theory to explain the behavior of consumers engaged in online transactions [4].

2.2. Composition of Network Transaction Costs. The above scholars started with Williams' transaction cost research and proposed the transaction cost factors that may arise in the online transaction process, but they put the research perspective more in the transaction process. We believe that from the perspective of consumers, the cost factors in online transactions can be summarized into the following categories [5].

2.2.1. Asset-Specific Cost. It is the investment of special equipment invested by consumers in order to achieve network transactions, such as computer equipment, network access equipment, and expenses.

2.2.2. Learning Cost. It is the cost that consumers pay for the smooth progress of online transactions and the decision to maximize the effectiveness of the transaction negotiation, such as network knowledge learning, online transaction negotiation skills learning, and lack of knowledge of online transactions in the initial stage of the transaction.

2.2.3. Search Cost. It is the cost of product quality and aftersales service that consumers must provide in order to find suitable products and trading partners.

2.2.4. Time Cost. It is the time cost that consumers pay to make a deal.

2.2.5. Monetary Cost. It is the monetary expenditure of the order, commodity price, distribution, maintenance, etc. paid by the consumer for the purchase of the product.

2.2.6. Risk Cost. It is the risk that consumers bear because of the uncertainty of online transactions.

\section{Research on Measurement Factors of E-Commerce Service Quality}

3.1. Definition of E-Commerce Service Quality. Broadly speaking, electronic services are based on the exchange of information to provide customers with a better experience. In a narrow sense, electronic services are services based on network delivery. Fan Wang and others proposed five components of electronic services, sorted by importance as follows: core services, convenience services, support services, complementary services, and user interfaces. Compared with the traditional business environment, electronic services are in the special environment of the Internet. 


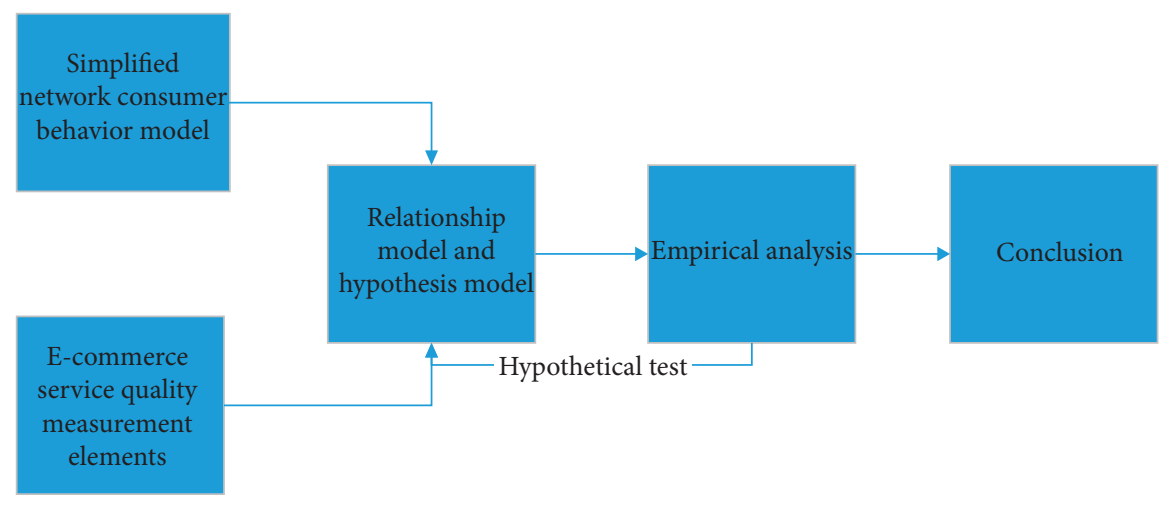

Figure 1: The paper design method process.

Electronic service providers deliver services to consumers "online." It is also composed of a series of activities and is holistic [6].

Generally speaking, the e-service quality in the e-commerce environment is the e-commerce service quality, which refers to the overall evaluation and judgment of the superiority of the service provided by the service provider in the online market. This paper defines the quality of e-commerce service as follows: the sum of the characteristics and characteristics of e-commerce services that can meet the requirements and potential needs, the degree to which e-commerce service can meet the needs of the serviced, and the minimum that the enterprise provides to satisfy the target customers. The service level is also the company that maintains this service level. The theoretical model of the sixdimensional e-commerce service quality of this study is shown in Figure 2.

Compared with the evaluation of traditional service providers, when customers accept e-commerce services, they are more likely to evaluate prepurchase services, purchase services, and postpurchase services throughout the process and results. For online consumers, the primary condition for securing their potential benefits is to develop high-quality e-commerce service quality standards. The openness and sharing characteristics of the network enable network consumers to more easily use the network tools to compare the technical characteristics, product prices, and service quality of e-commerce service providers [7], for example, comparison network [8]. Online reviews and online word of mouth have a major impact on online consumers' buying decisions. Therefore, e-commerce services play an important role in online consumers. Internet consumers want to demand no lower than the quality of offline services and even higher requirements.

In e-commerce activities, the face-to-face interaction between service personnel and customers has been replaced by website interface, website instant messaging tools, etc., but the quality of service can still be divided into technical quality and functional quality [9]. However, the technical quality and functional quality here no longer refer to the quality of the process and the quality of the results but are given new meaning. Functional quality focuses primarily on the quality of the website itself, while technical quality focuses on the quality of the network service. Functional quality plays a key role. To improve the technical quality, the actual service provided by the website should be consistent with the promised service, respond to the customer's needs in a timely manner, and give the correct solution to meet or exceed the customer's needs or expectations. If the customer is dissatisfied with the technical quality, the customer is likely to be lost and may no longer visit the company website or may not shop from the website. In a networked environment, the cost of replacing an e-commerce service provider is very low, and it is very easy to transfer to a competitor's website. Therefore, the above situation is very likely.

3.2. Quality of Service Measurement Model. In the traditional environment, the most commonly used quality of service measurement model SERVQUAL model is described below.

American marketing scientist Parasuraman (1985) and others pointed out that perceived service quality is "a comprehensive judgment or opinion made by the customer subjective and related to the quality of the service." They put forward the "gap theory" on the customer's measurement of service quality. They believe that the customer's perceived service quality depends on the degree of difference between the customer's perception and the customer's expectations in the service process. When the customer's actual perceived service quality meets or exceeds their expected service quality, their perceived service quality is good. When they actually felt that the quality of service was not as good as the expected quality of service, their perceived service quality was poor [10]. They conducted an experimental study in 1985 and found ten measurement elements of perceived service quality: perceptibility, reliability, responsiveness, communication, trust, security, competence, sincerity, understanding of customers, and acceptability [11]. These ten factors are further streamlined to five: perceptibility, reliability, responsiveness, assurance, and affection. Perceptibility refers to the "tangible part" of a service product; reliability means that the enterprise can perform reliably and accurately. Responsiveness means that the company is willing to help customers and provide fast service; guaranty refers to the friendly attitude of the service personnel and the ability to do the job; emotionality means that the company should sincerely care about the customers and understand 


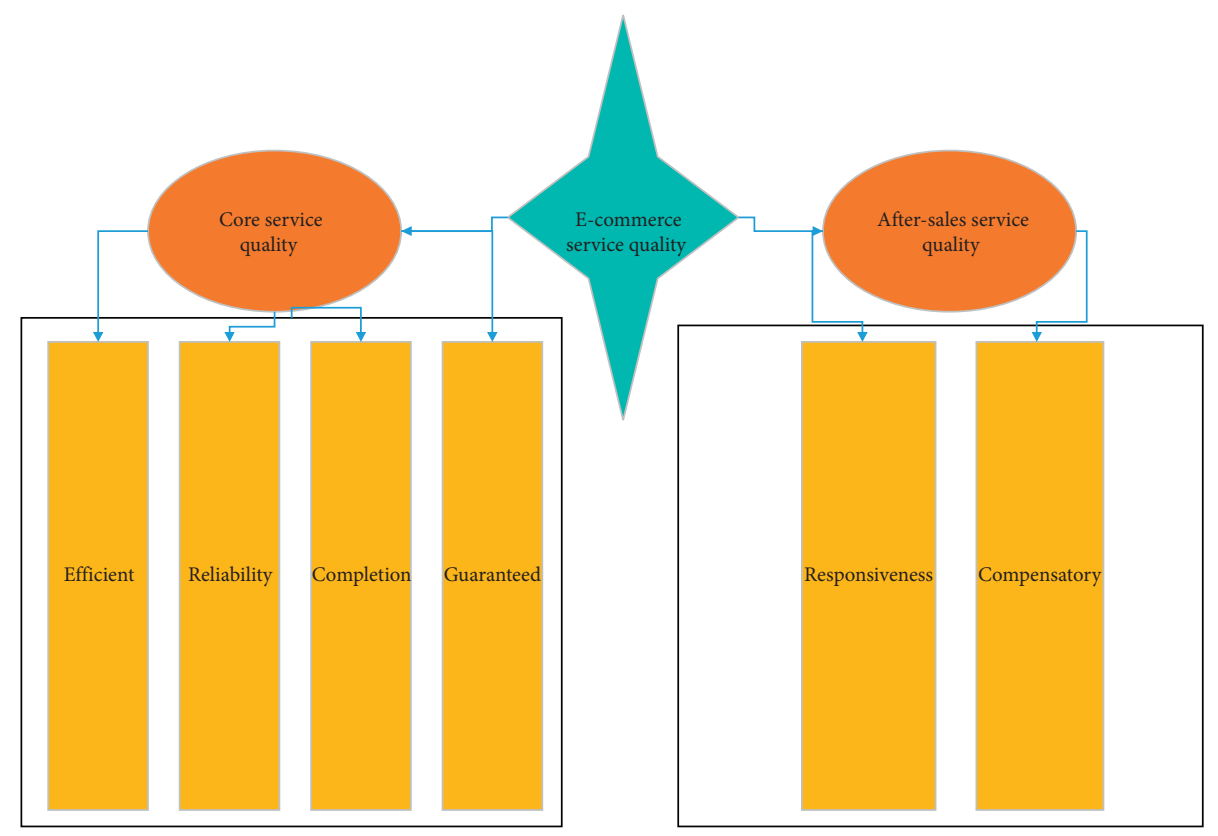

FIGURE 2: The theoretical model of service quality of e-commerce.

their actual needs. On this basis, Parasuraman, Zeithaml and Berry have established a service quality model, SERVQUAL (short for service quality) to measure the quality of service of the enterprise. It uses the difference function to measure the quality of service, i.e., SERVQUAL $=f$ (perceive an expectation). The SERVQUAL model includes a total of 22 measurement indicators (see Table 1).

In general, the quality of electronic service is that the electronic service provider delivers the service to the customer through the special environment of "online," which includes the overall process, such as the process of browsing the website, the process of goods delivery, and the customer's overall service. The degree of evaluation and so on are all part of the quality of electronic services [12].

The service quality of e-commerce companies can be divided into two parts: technical quality and functional quality [13]. Moreover, functional quality still plays a key role. For example, enabling customers to quickly find the company's website is a prerequisite for starting a transaction. Improving technical quality means that the actual service is consistent with the promised service and can meet or exceed customer needs or expectations. Because it is easy for customers to transfer to competitor's website in the network environment, the above situation is very likely to happen [14].

3.3. Measurement Elements of E-Commerce Service Quality. Based on the SERVQUAL model and reading a large number of documents, combined with the comments of Chinese customers on online shopping, this paper proposes that the measurement elements of e-commerce service quality are mainly efficient, reliable, complete, private, responsive, and compensated. Table 2 shows a description of the significance of PZM to the dimensions in the model [15].
After many studies, this study believes that since responsiveness and contact cover the attitude and efficiency of after-sales service quality, the effects of the two influence each other, so they can be combined into the responsiveness of after-sales service as a whole. Therefore, this study uses two major service areas and six dimensions of the system to study the quality of e-commerce services [16].

3.3.1. Ease of Use. Ease of use includes two main aspects: on the one hand, sufficient functionality, and on the other hand, friendly interface design. Some very useful features, such as search and download capabilities, are necessary for customers to continue to access smoothly. One of the main reasons why customers use the Internet as a purchasing channel is its convenience [17]. In other words, they want to be able to easily complete the transaction on the website [18]. For example, online banking customers want to be able to autopay electronically, view banking conditions for a month, buy stocks and insurance, and avail other financial services. In this sense, having a full range of product lines and service lines can attract a large number of customers to visit their websites. Many customers want to find and discover products and services that are not easily found or not available in traditional local stores [19]. Similarly, customers can view their own transactions at any time and attract customers who are not satisfied with the current service. Therefore, having enough features is one of the keys to a website's ability to gain customer loyalty [20].

3.3.2. Reliability. Reliability refers to the ability of an enterprise to accurately complete a promised service. This attribute means that the company must deliver the service accurately as promised. Reliability service actually requires the company to avoid mistakes because service errors will 
TABLE 1: SERVQUAL measurement scale.

\begin{tabular}{|c|c|}
\hline Latitude & Measurement project \\
\hline Reliability & $\begin{array}{l}\text { When a company promises to do something in a certain time, it will keep its promise } \\
\text { The company tries its best to help customers solve problems when customers encounter problems } \\
\text { A company provides good service from beginning to end } \\
\text { A company provides services when it is promised } \\
\text { A company informs customers when they start to provide services }\end{array}$ \\
\hline Responsive & $\begin{array}{c}\text { Employees provide prompt and timely service } \\
\text { A company's employees are always happy to help customers } \\
\text { Employees respond to customer requests in a timely manner no matter how busy }\end{array}$ \\
\hline Guarantee & $\begin{array}{l}\text { The behavior of a company's employees is trustworthy } \\
\text { A company employee should be trustworthy } \\
\text { A company employee should always treat customers with enthusiasm } \\
\text { A company employee should have sufficient knowledge to answer customer questions }\end{array}$ \\
\hline Empathy & $\begin{array}{l}\text { A company gives individual attention to customers } \\
\text { A company has employees who give individual attention to customers } \\
\text { A company understands the most interesting things of customers } \\
\text { A company is very concerned about the personal interests of customers } \\
\text { The employees of a company understand the needs of customers }\end{array}$ \\
\hline Perceived & $\begin{array}{l}\text { A company has modern equipment } \\
\text { The appearance of a company's equipment is attractive } \\
\text { The employees of a company are dressed properly, clean, and tidy } \\
\text { Complete information about the services provided } \\
\text { A company has a convenient time to work }\end{array}$ \\
\hline
\end{tabular}

TABLE 2: Explanation of PZM's meaning of the dimension of online service quality.

\begin{tabular}{|c|c|}
\hline Online service quality & Meaning of the dimension \\
\hline Efficiency & The difficulty and speed of access to the site \\
\hline Fulfillment completion & The commitments provided by the website and related projects are fulfilled \\
\hline System availability & Station correct technical implementation \\
\hline & Website security and customer information \\
\hline Privacy & The degree to which the interest is protected \\
\hline Responsiveness & $\begin{array}{l}\text { Effectively processed and reversed through the website } \\
\text { Feed the question }\end{array}$ \\
\hline Compensation & $\begin{array}{l}\text { The website is for the questions that appear } \\
\text { The degree to which the customer is compensated }\end{array}$ \\
\hline Contact & Contact by phone or online way to provide assistance \\
\hline
\end{tabular}

bring losses to the enterprise, not only direct economic losses but also mean the loss of many potential customers [21].

Some online customers are disappointed with the reliability of the services provided by Internet companies. The reason is mainly because the coordination between the internal and external of the company is not good. Internal cooperation includes communication between different functional departments. External collaboration means collaboration between supply chain partners. In fact, products and services can be regularly checked and updated [22].

Completion requires a good supply of facilities, which is a major task of Internet commerce. Many online retailers use third-party service providers to complete their orders because they often have difficulty controlling the quality and timing of delivery.
3.3.3. Reactivity. Responsiveness means being willing to provide consumers with fast and efficient services. In the network environment, because the face-to-face service is gone, it seems difficult to intuitively judge the attitude and performance of the service personnel [23]. In fact, the response is reflected in the response mode and response time of the customer to the customer consultation or complaint, ready to help the customer. The willingness to order comes from the speed of confirmation, allocation, feedback, and delivery. This attribute emphasizes the immediate handling of consumer requests, questions, complaints, and questions. Consumers feel the responsiveness of the service based on the length of time they wait for help from the site staff, answering questions and solving problems. One of the advantages of Internet commerce is that it improves the efficiency of transactions and greatly shortens the processing time of transactions [24]. In order to provide timely service 
and help customers solve their problems, this requires timely interaction with customers. Unlike tangible stores, Internet business people often lack timely interaction with customers [2].

3.3.4. Security. Security means ensuring the security of online transactions and the confidentiality of personal privacy. In the bad environment of the Internet, because customers and companies are not in face-to-face contact, customers often think that there are risks in purchasing on the Internet, especially the use of credit cards to make customers more worried about information leakage such as personal privacy or misuse of personal information. For example, the application passwords on the internet are leaked, and the subsequent property is lost; important secrets and business information are revealed; the office system is attacked by hackers, causing economic losses or loss of important data. Therefore, no matter what company is using the Internet to provide customers with perfect and thoughtful service, it must prevent sudden damage.

3.3.5. Customer Care. Customer care, also known as empathy, refers to caring for customers, understanding customer needs, and making the entire service process "human." Although it is a face-to-face contact, it is necessary to make customers feel valued and cared for [25]. SERVQUAL measurement models and self-service technology research have shown that the company's concern for customers is an important measure of customer perceived service quality. In the Internet business environment, it is also very important to care for customers and provide humanized services to customers [26]. Foreign studies have found that about two-thirds of customers have abandoned their shopping carts before they check out on the website because they are not cared for. This means that $2 / 3$ of the customers want to trade online, but they give up the deal because they lack enough care. With the development of the economy and the progress of society, more and more customers are pursuing individualized consumption. Whether it is clothing, furniture, electrical appliances, or communication equipment, all show the trend of individualization.

3.3.6. Customer Trust. Customer trust means that one party of the transaction (the customer) believes that the other party of the transaction (online business) is honest and trustworthy. Trust is the most important concept in relationship marketing. The definition of trust is not uniform in academia. According to the commitment-one trust theory, trust is "reliability and loyalty to trading partners." The above definition of trust points to two dimensions of trust: (1) credibility - the degree of trust in the ability of a trading partner to effectively perform work. Reputation includes ability, consistency, stability, sexual behavior, and other aspects related to the company's reputation. (2) Benevolence: the degree of belief in the intention and motivation of the altruistic (the other party) when the trading partner does not consider the situation in the new situation or commitment.

\section{Relationship Model and Empirical Research on Network Consumer Behavior and E-Commerce Service Quality}

4.1. The Measurement Factors of Business Service Quality. Table 3 summarizes the measurement items for each metric. A total of six elements and 28 measurement items need to be measured.

4.1.1. Research Methods and Research Objects. This study uses the method of issuing questionnaires. In the questionnaires, the judgment sampling method in the nonprobability sampling method is adopted. This method is applicable to exploratory investigations such as market research.

The survey sample includes college students and employees of enterprises and institutions. We only choose people over 18 years old as the research object. This is because these groups generally have certain disposable income and have certain network experience.

4.1.2. Sample Size and Accuracy. In this study, 200 questionnaires were distributed in Changchun in March 2007, and consumers with online consumption experience were invited to fill out the questionnaire. As of April 1, a total of 172 questionnaires were collected, 52 questionnaires that were not carefully completed were removed (if all questions were answered with the same answer or multiple questions were not answered), 120 valid questionnaires were collected, and the effective recovery rate was collected.

When determining the appropriate sample size, we consider three elements:

(1) The overall size of the difference that can be assured.

(2) Expected accuracy.

(3) The confidence required for the estimate.

$$
n=\frac{t^{2} \mathrm{pq}}{e^{2}}
$$

where $n$ is the sample size; $t$ is the standard error associated with the selected confidence interval; $p$ is the estimated difference of the population; $q=1-p$; and $e$ is an acceptable error.

When using the percentage rate method, the biggest difference is that the two answers each account for $50 \%$, which is $50 \%$ multiplied by $50 \%$, the maximum possible value. With a $95 \%$ confidence interval, $t=1.96$, the accuracy of this survey sample is

$$
e^{2}=\frac{t^{2} \mathrm{pq}}{n}=\frac{1.96^{2} * 0.5^{2}}{120}=0.008
$$

That is, the sample accuracy of this survey is $92 \%$. 
TABLE 3: The measurement factors of business service quality.

\begin{tabular}{|c|c|}
\hline Variable & Measurement item \\
\hline Ease of use & $\begin{array}{l}\text { Transaction is easy to complete } \\
\text { Website is easy to login } \\
\text { Searching for the information you need is easy } \\
\text { Service content is easy to understand } \\
\text { Website content can meet customer needs } \\
\text { Can check the transaction status at any time } \\
\text { Transaction is easy to complete }\end{array}$ \\
\hline Reliability & $\begin{array}{l}\text { Transaction is accurate } \\
\text { According to personal information record } \\
\text { Business can fulfill the promise } \\
\text { Product service can be delivered on time }\end{array}$ \\
\hline Reactivity & $\begin{array}{l}\text { Can give quick response } \\
\text { Can solve the problem quickly } \\
\text { Correct problem solving } \\
\text { Company personnel have the ability to answer questions } \\
\text { Online company can handle complaints in a friendly way }\end{array}$ \\
\hline Security & $\begin{array}{l}\text { Online trading is very safe } \\
\text { Providing personal information is very safe } \\
\text { Online company will not misuse personal information }\end{array}$ \\
\hline Customer Care & $\begin{array}{c}\text { Online company personnel can act according to my requirements } \\
\text { Online company can record and update my preferences } \\
\text { Online employees can understand my specific needs } \\
\text { Online company will tell me some important information soon } \\
\text { Online company's free service is rich } \\
\text { Online company personnel can act according to my requirements }\end{array}$ \\
\hline Customer Trust & $\begin{array}{c}\text { Trust online company } \\
\text { Online company has a good reputation } \\
\text { Online company is very honest } \\
\text { Transaction is fair }\end{array}$ \\
\hline
\end{tabular}

$$
\begin{aligned}
p_{i}^{j}(k) & =p_{i}^{j}(k-1)-a \frac{\partial e}{\partial p_{i}^{j}}, \\
\frac{\partial e}{\partial p_{i}^{j}} & =\frac{\left(y_{d}-y_{c}\right) a^{j}}{\sum_{j=1}^{n} a^{j} x_{i}} .
\end{aligned}
$$

In equations (3) and (4), $p_{j}^{i}$ is the neural network coefficient; $a$ is the network learning rate; $x_{i}$ is the network input parameter; and $a_{j}$ is the product of the input parameter membership. Parameter correction:

$$
\begin{aligned}
& c_{i}^{j}(k)=c_{i}^{j}(k-1)-\beta \frac{\partial e}{\partial c_{i}^{j}}, \\
& b_{i}^{j}(k)=b_{i}^{j}(k-1)-\beta \frac{\partial e}{\partial b_{i}^{j}},
\end{aligned}
$$

where $c$ and $b$ are, respectively, the center and width of the membership function. The conceptual model of relationship between e-commerce service quality and online consumer behavior is shown in Figure 3.

\subsection{Data Analysis and Results}

4.2.1. Descriptive Analysis of Data. The data collected in this paper are mainly aimed at adults and people of all income levels. In order to obtain different samples, social workers in formal jobs are mainly selected. In the case of data analysis, it is generally necessary to conduct descriptive statistical analysis of the data to discover its inherent laws and then select a method for further analysis. This step is a prerequisite for correct statistical inference below [2]. This paper conducts a descriptive statistical analysis of e-commerce service quality measurement elements and e-commerce service quality, online consumer attitudes, and behavioral intentions (see Tables 4 and 5). Statistical analysis results are shown in Figures 4 and 5.

It can be seen from the above two figures and two tables that consumers' consumer psychology and consumer behavior have a defined correlation; as a whole, there is a positive proportional relationship, and a linear relationship is also present.

4.3. Correlation Analysis of Data. In an effective indicator system (questionnaire), several indicators under each attribute have a strong linear correlation. However, the correlation of the indicators under each attribute in the initial screening index system is different, so they should be analyzed. Correlation analysis is a measure of the statistical relationship between things. The means and tools of strength and weakness measure the closeness between variables through correlation coefficients. The correlation coefficient is between -1 and 1 . 


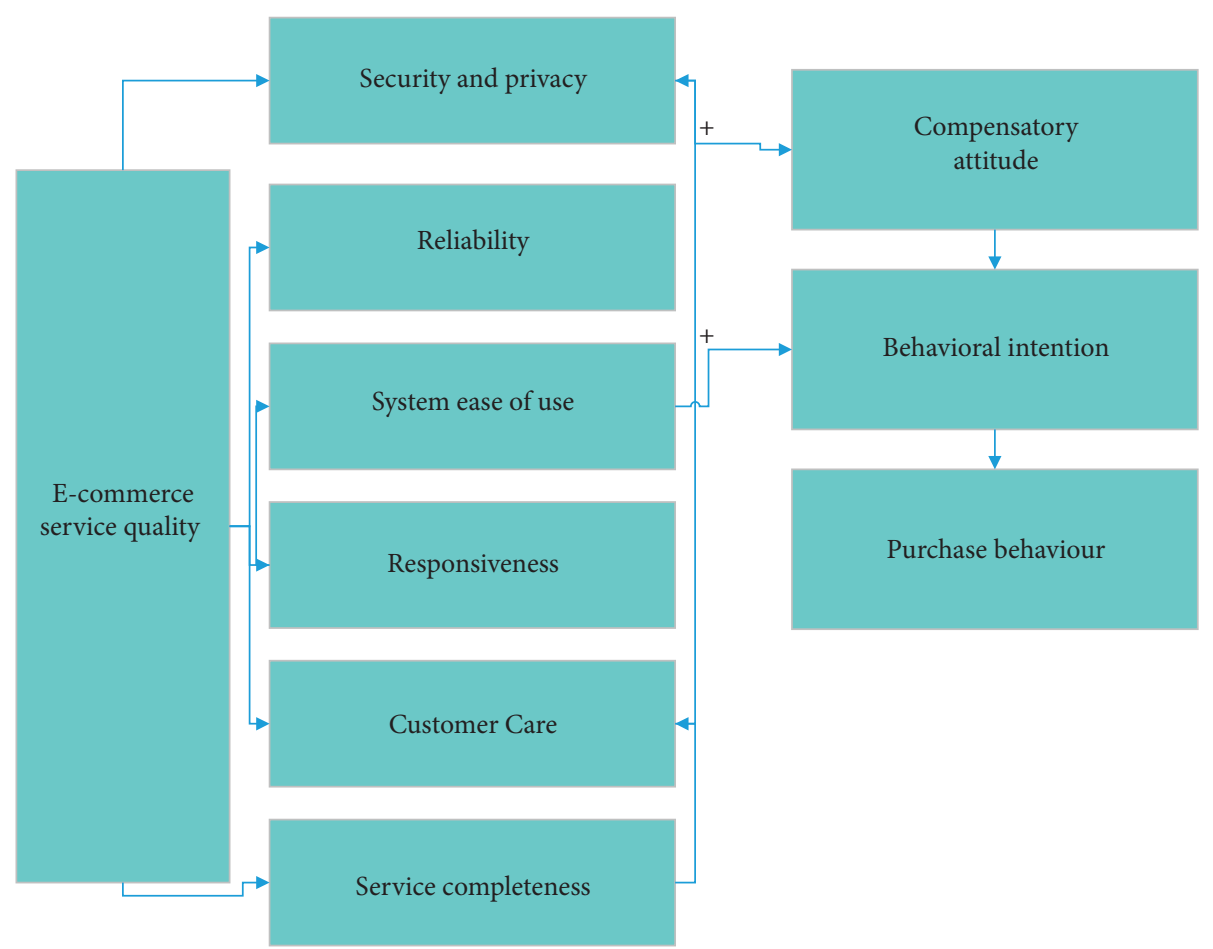

FIGURE 3: Conceptual model of relationship between e-commerce service quality and online consumer behavior.

TABle 4: Descriptive analysis for measuring the quality of business service quality.

\begin{tabular}{lccccc}
\hline Variables & $N$ & Minimum & Maximum & Mean & Standard deviation \\
\hline Ease of use & 120 & 2.17 & 5.00 & 3.8417 & 0.61336 \\
Reliability & 120 & 2.00 & 5.00 & 3.7188 & 0.69100 \\
Reactivity & 120 & 1.60 & 5.00 & 3.5283 & 0.67751 \\
Security & 120 & 1.00 & 5.00 & 3.1889 & 0.84872 \\
Customer care & 120 & 1.20 & 5.00 & 3.4167 & 0.70034 \\
Customer trust & 120 & 1.80 & 5.00 & 3.5017 & 0.71054 \\
\hline
\end{tabular}

TABle 5: Descriptive analysis of business service quality, online consumer attitude, and behavior intention.

\begin{tabular}{|c|c|c|c|c|c|}
\hline Variables & $N$ & Minimum & Maximum & Mean & Standard deviation \\
\hline E-commerce service quality & 120 & 2.00 & 5.00 & 3.8250 & 0.59285 \\
\hline Attitude & 120 & 2.00 & 5.00 & 3.9167 & 0.76514 \\
\hline Behavioral intention & 120 & 1.67 & 5.00 & 3.8472 & 0.82094 \\
\hline Security & 120 & 1.00 & 5.00 & 3.1889 & 0.84872 \\
\hline Customer care & 120 & 1.20 & 5.00 & 3.4167 & 0.70034 \\
\hline Customer trust & 120 & 1.80 & 5.00 & 3.5017 & 0.71054 \\
\hline
\end{tabular}

The above method is used to analyze the e-commerce service quality measurement factors and the attitudes of network consumers. The results are shown in Table 6 [25].

It can be seen from Table 6 that the correlation coefficient between the six measurement elements of e-commerce service quality and the attitude of network consumers is positive, among which there are four measurement factors of ease of use, reliability, responsiveness, and customer trust and network consumption. The attitude of $P$ value is 0 . The 1 level is significantly correlated. The security and online consumer attitudes are significantly correlated with the $P$ value of 0.05 . The correlation between customer care and online consumer attitude is not significant. Relevant analysis diagram of business service quality measurement elements and network consumer attitudes is shown in Figure 6.

4.4. Regression Analysis of Data. Correlation analysis is closely related to regression analysis. They are statistical methods for studying the linear relationship between variables, but there are differences between the two. The 


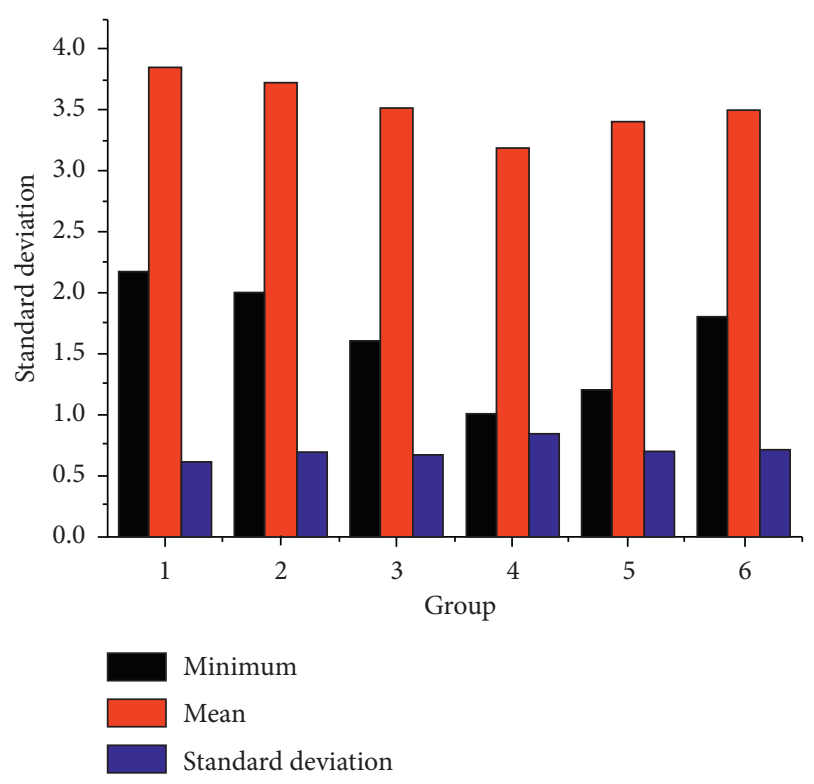

FIgURE 4: Service quality analysis chart.
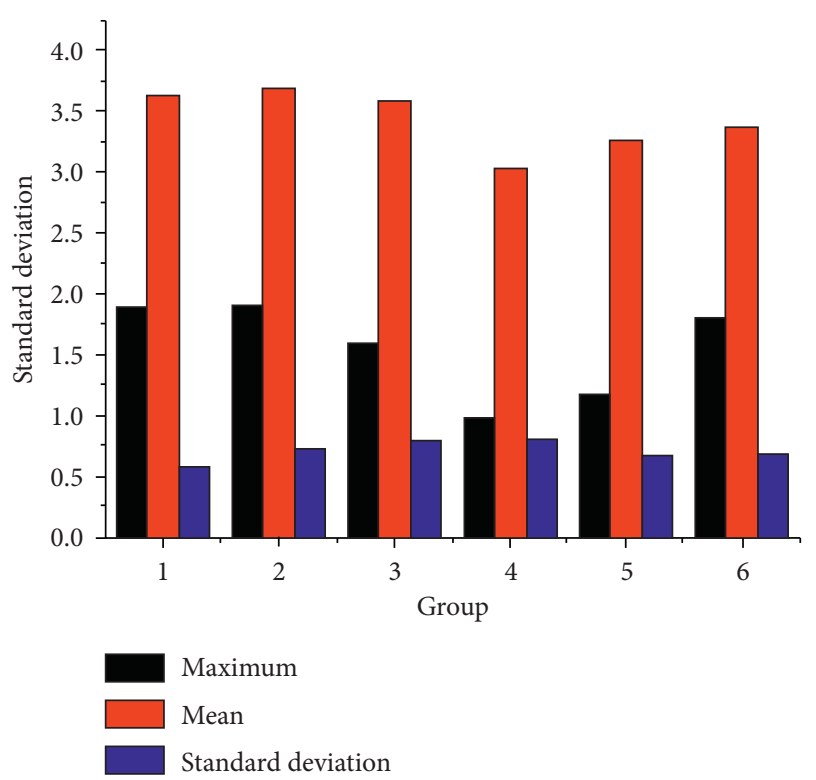

FIGURE 5: Behavioral intention analysis diagram.

TABLE 6: Correlation analysis of measurement elements of business service quality.

\begin{tabular}{lcc}
\hline $\begin{array}{l}\text { Network } \\
\text { consumer attitude }\end{array}$ & $\begin{array}{c}\text { Pearson correlation } \\
\text { coefficient }\end{array}$ & Significant sig. (2-tailed) \\
\hline Ease of use & 0.331 & 0.000 \\
Reliability & 0.297 & 0.001 \\
Reactivity & 0.246 & 0.007 \\
Security & 0.188 & 0.039 \\
Customer care & 0.087 & 0.343 \\
Customer trust & 0.237 & 0.009 \\
\hline
\end{tabular}

variables studied in the correlation analysis are regarded as random variables, and only the linear relationship between the variables is studied, and the variables studied in the regression analysis are divided into dependent variables and independent variables.

This part uses multiple linear regression analysis to verify the hypothesis of the model through regression analysis of various factors on e-commerce service quality. Regression analysis is carried out on the six measurement elements of e-commerce service quality and e-commerce service quality, so as to obtain the influence of each element on e-commerce service quality, and then the standard regression equation of e-commerce service quality and its measurement elements can be obtained. The regression method used is a combination of methods (stepwise). The results are shown in Table 7 [25].

$F$ test: the larger the $F$ value, the better the regression effect; when the Sig. $F$ value is $<0.05$, it indicates that the independent variable tested can describe the dependent variable.

$T$ test: when $n>5$, if $a=0.05$, and then when $t>2$, it can be judged that the regression coefficient at this time is not 0 , and the corresponding variable can be used as an explanatory variable to describe the dependent variable. According to the standard, the regression results from the table show that the equations obtained by regression analysis of the six independent variables designed for the dependent variables satisfy $F$.

The result shows that the regression equation established between the above six independent variables and the dependent variable meets the test requirements. In addition, it can be seen that the complex coefficient (R-square) is 0.21 , indicating that the regression equation can explain $21 \%$ of the total variation.

4.4.1. Regression Analysis between E-Commerce Service Quality Measurement Factors and Online Consumer Behavior Intentions. As before, we separately analyze the online consumer behavior intention and the e-commerce service quality's six measurement factors. The specific analysis results are shown in Table 7 [26]. Regression analysis diagram of six measurement factors is shown in Figure 7.

Complex decision coefficient $(\mathrm{R}$-square $)=0.211$.

$F$ value $=5.030 ; p$ value $=0.00 .000$.

Correct $\mathrm{Rz}$ (adjusted $R)=0.169$.

From the regression results, it can be seen that customer care does not enter the equation, indicating that customer care has no significant effect on the online consumer behavior intention. According to the order of the other five factors in the equation, we obtain the regression equation $[27,28]$ :

online consumer intent $=0.329 *$ customer trust +0.309

$$
\begin{aligned}
& * \text { ease of use }+0.237 * \text { reactivity } \\
& +0.193 * \text { reliability }+0.221 \\
& * \text { security. }
\end{aligned}
$$




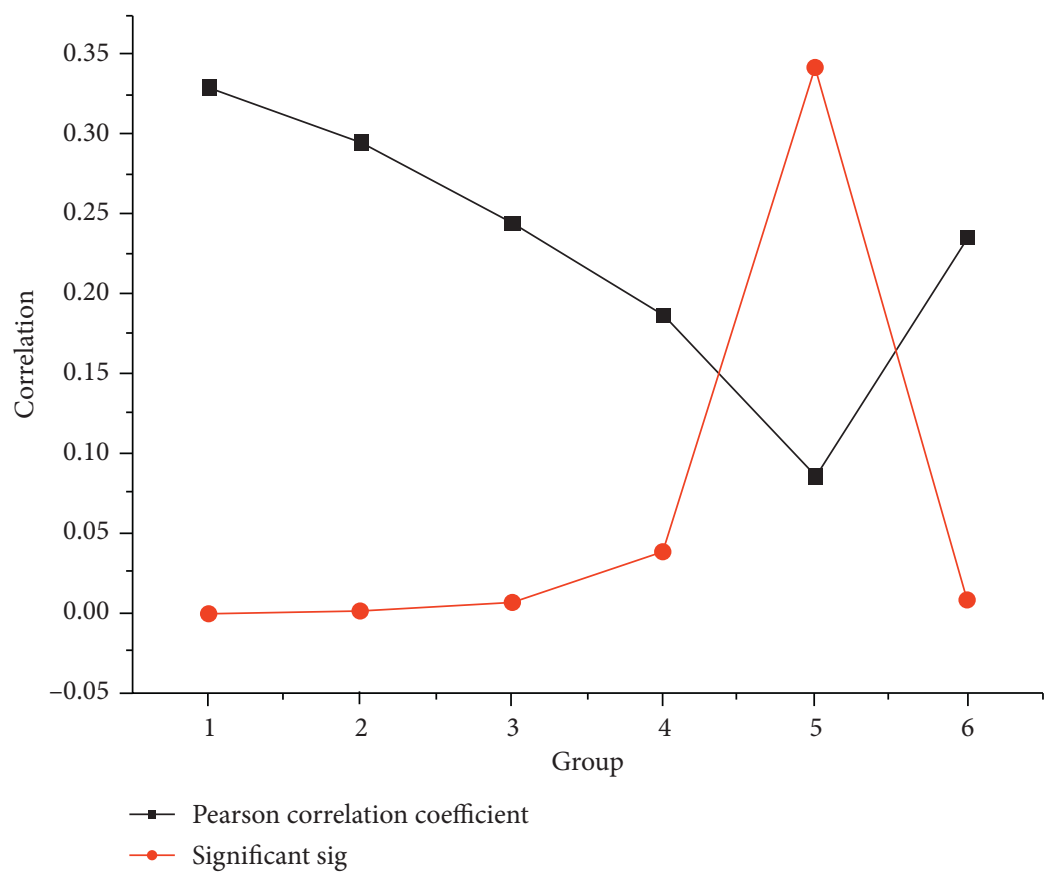

FIGURE 6: Relevant analysis diagram of business service quality measurement elements and network consumer attitudes.

TABLE 7: Regression analysis of e-commerce service quality.

\begin{tabular}{lcccc}
\hline Equations in the variable & Regression coefficient & Standard regression coefficient & $T$ value & Significant probability \\
\hline Ease of use & 0.414 & 0.309 & 3.535 & 0.001 \\
Reliability & 0.229 & 0.193 & 2.134 & 0.035 \\
Reactivity & 0.287 & 0.237 & 2.650 & 0.009 \\
Security & 0.214 & 0.221 & 2.466 & 2.569 \\
Customer care & 0.087 & 0.343 & 3.789 & 0.015 \\
Customer trust & 0.381 & 0.329 & & 0.000 \\
\hline
\end{tabular}

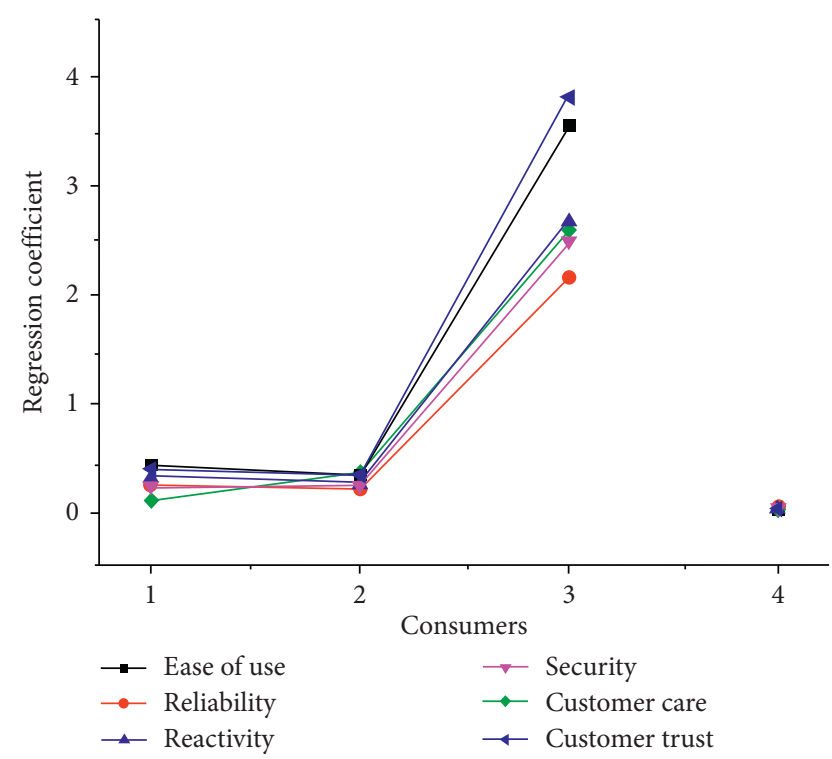

FIGURE 7: Regression analysis diagram of six measurement factors.
The results also show that $\mathrm{H} 3 \mathrm{a}, \mathrm{H} 3 \mathrm{~b}, \mathrm{H} 3 \mathrm{c}, \mathrm{H} 3 \mathrm{~d}$, and $\mathrm{H} 3 \mathrm{f}$ are assumed to be true, assuming that $\mathrm{H} 3 \mathrm{e}$ does not hold [29].

\subsubsection{The Third Set of Assumptions}

$\mathrm{H} 3 \mathrm{a}$ : from the results of regression analysis, there is a significant correlation between ease of use and behavioral intentions of online consumers. Empirical studies show that $\mathrm{H} 3 \mathrm{a}$ is assumed to be established.

$\mathrm{H} 3 \mathrm{~b}$ : the empirical results show that there is a positive relationship between reliability and network consumer behavior intention, supporting hypothesis $\mathrm{H} 3 \mathrm{~b}$.

$\mathrm{H} 3 \mathrm{c}$ : the results of regression analysis show that reactivity has a direct positive impact on the behavioral intention of online consumers, assuming $\mathrm{H} 3 \mathrm{c}$ is established.

$\mathrm{H} 3 \mathrm{~d}$ : the empirical results show that security has a direct positive impact on the behavior of online consumers, supporting hypothesis $\mathrm{H} 3 \mathrm{~d}$. 
H3e: the empirical results show that customer care has no significant effect on the behavior of online consumers, so it is assumed that $\mathrm{H} 3 \mathrm{e}$ is not established.

H3f: the empirical results show that customer trust has a positive correlation between online consumer behavior intentions, supporting hypothesis H3f.

This section is the main part of the thesis. First, we introduce the conceptual model and model hypothesis proposed by us and explain the research design and data collection of this research. Finally, through data analysis, the relationship between online consumer behavior and e-commerce service quality is clarified.

\section{Conclusion}

This article identifies e-commerce services. The quality measurement elements are ease of use, reliability, responsiveness, safety, customer care, and customer trust, which are meaningful for the company to rationally use limited resources. This paper proposes a simplified relationship model between online consumers based on attitudes and intentions combined with $5 \mathrm{G}$ technology to track consumer behavior and e-commerce service quality. On this basis, the hypothesis of e-commerce service quality and online consumer attitudes and behavior intentions is proposed. The analysis verified and clarified the impact of e-commerce service quality on online consumer behavior and provided a basis for companies to better participate in the development of the $\mathrm{B} 2 \mathrm{C}$ market.

\section{Data Availability}

No data were used to support this study.

\section{Conflicts of Interest}

The author declares that there are no conflicts of interest.

\section{Acknowledgments}

This study was supported by the Evaluation Research of Comprehensive Competitiveness of Modern Service Industry of Guanzhong-Tianshui Economic Zone on "One Belt One Road” Strategy (XJ150230).

\section{References}

[1] K. J. Li and S. Jain, "Behavior-based pricing: an analysis of the impact of peer-induced fairness," Social Science Electronic Publishing, vol. 62, no. 2, pp. 2705-2721, 2016.

[2] P. Gupta and J. Harris, "How e-WOM recommendations influence product consideration and quality of choice: a motivation to process information perspective," Journal of Business Research, vol. 63, no. 9, pp. 1041-1049, 2010.

[3] E. Carrillo-Álvarez, J. Riera-Romaní, and O. Canet-Vélez, "Social influences on adolescents' dietary behavior in Catalonia, Spain: a qualitative multiple-cases study from the perspective of social capital," Appetite, vol. 12, no. 3, p. 289, 2018.
[4] R. K. Steele, "A perspectival review of rail behavior at the facility for accelerated service testing," Canadian Metallurgical Quarterly, vol. 22, no. 3, pp. 353-367, 2014.

[5] G. Bene and D. Dieks, "A perspectival version of the modal interpretation of quantum mechanics and the origin of macroscopic behavior," Foundations of Physics, vol. 32, no. 5, pp. 645-671, 2002.

[6] Y. Yan, P. Guo, B. Cheng, and Z. Zheng, "An experimental case study on the relationship between workload and resource consumption in a commercial web server," Journal of Computational Science, vol. 25, pp. 183-192, 2017.

[7] J. Li, Z. Zheng, Q. Tian, G. Zhang, F. Zheng, and Y. Pan, "Research on tridiagonal matrix solver designing based on combination of processors," Computers \& Electrical Engineering, vol. 62, pp. 1-16, 2017.

[8] X. Li, Z. Lv, Z. Zheng, C. Zhong, I. H. Hijazi, and S. Cheng, "Assessment of lively street network based on geographic information system and space syntax," Multimedia Tools and Applications, vol. 76, no. 17, pp. 17801-17819, 2017.

[9] S. Pan, W. Sun, and Z. Zheng, "Video segmentation algorithm based on superpixel link weight model," Multimedia Tools and Applications, vol. 76, no. 19, pp. 19741-19760, 2017.

[10] S. Shivani, S. Tiwari, K. K. Mishra, Z. Zheng, and K. Arun, "Providing security and privacy to huge and vulnerable songs repository using visual," Multimedia Tools and Applications, vol. 77, no. 9, pp. 11101-11120, 2017.

[11] M. Chahal, S. Harit, K. K. Mishra, A. Sangaiah, and Z. Zheng, "A survey on software-defined networking in vehicular ad hoc networks: challenges, applications and use cases," Sustainable Cities and Society, vol. 35, no. 11, pp. 830-840, 2017.

[12] J. T. Child and D. A. Westermann, "Let's be facebook friends: exploring parental facebook friend requests from a communication privacy management (CPM) perspective," Journal of Family Communication, vol. 13, no. 1, pp. 46-59, 2013.

[13] G. Zhao, "Energy-spectral-efficiency analysis and optimization of heterogeneous cellular networks: a large-scale userbehavior perspective," IEEE Transactions on Vehicular Technology, vol. 1, no. 1, p. 99, 2018.

[14] T. D. Hackenberg, "Realism without truth: a review of Giere's science without laws and scientific perspectivism," Journal of the Experimental Analysis of Behavior, vol. 91, no. 3, pp. 391-402, 2013.

[15] F. Lehner, "Cognitive structure, uncertainty, and the rationality of political action: a synthesis of economic and psychological perspectives," European Journal of Political Research, vol. 3, no. 3, pp. 275-291, 2010.

[16] D. Boonpakdee, W. Surareungchai, and C. Laovorakiat, "Exploring non-linearities of carbon-based microsupercapacitors from an equivalent circuit perspective," Journal of Materials Chemistry A, vol. 6, no. 16, pp. 7162-7167, 2018.

[17] X. Xu, B. Shen, X. Yin et al., "Edge server quantification and placement for offloading social media services in industrial cognitive IoV," IEEE Transactions on Industrial Informatics, vol. 17, no. 4, pp. 2910-2918, 2020.

[18] X. Xu, X. Zhang, X. Liu, J. Jiang, L. Qi, and M. Zakirul Alam, "Adaptive computation offloading with edge for 5G-envisioned Internet of connected vehicles," IEEE Transactions on Intelligent Transportation Systems, vol. 8, pp. 1-10, 2020.

[19] F. Li, Z. Yu, and C. Qin, "Constructive texture steganography based on compression mapping of secret messages," CMEScomputer Modeling in Engineering \& Sciences, vol. 124, no. 1, pp. 393-410, 2020. 
[20] Z. Gao and S. Wan, "Exploring deep learning for view-based 3D model retrieval," ACM Transactions on Multimedia Computing, Communications, and Applications, vol. 16, no. 1, pp. 1-21, 2020.

[21] C.H. Chen, "An arrival time prediction method for bus system," IEEE Internet of Things Journal, vol. 5, no. 5, pp. 4231-4232, 2018

[22] Y. Xi, Y. Zhang, S. Ding, and S. Wan, "Visual question answering model based on visual relationship detection," Signal Processing: Image Communication, vol. 80, Article ID 115648, 2020.

[23] A. Zhou, S. Wang, S. Wan, and L. Qi, "LMM: latency-aware micro-service mashup in mobile edge computing environment," Neural Computing and Applications, vol. 1-15, 2020.

[24] F. Yin, Y. Wang, J. Liu, and M. Ji, "Enhancing embeddingbased Chinese word similarity evaluation with concepts and synonyms knowledge," CMES-computer Modeling in Engineering \& Sciences, vol. 124, no. 2, pp. 747-764, 2020.

[25] S. Wan, Y. Xia, L. Qi, Y. H. Yang, and M. Atiquzzaman, "Automated colorization of a grayscale image with seed points propagation," IEEE Transactions on Multimedia, vol. 22, no. 7, pp. 1756-1768, 2020.

[26] S. Wan, X. Xu, T. Wang, and Z. Gu, “An intelligent video analysis method for abnormal event detection in intelligent transportation systems," IEEE Transactions on Intelligent Transportation Systems, vol. 12, pp. 1-9, 2020.

[27] S. Wan, R. Gu, T. Umer, K. Salah, and X. Xu, "Toward offloading Internet of vehicles applications in 5G networks," IEEE Transactions on Intelligent Transportation Systems, vol. 6, pp. 1-9, 2020.

[28] Z. Gao, H. Xue, and S. Wan, "Multiple discrimination and pairwise CNN for view-based 3D object retrieval," Neural Networks, vol. 125, pp. 290-302, 2020.

[29] S. Wan and S. Goudos, "Faster R-CNN for multi-class fruit detection using a robotic vision system," Computer Networks, vol. 168, Article ID 107036, 2020. 